Published in final edited form as:

Gynecol Oncol. 2014 March ; 132(0 1): S26-S32. doi:10.1016/j.ygyno.2013.12.038.

\title{
Cervical Cancer Control for Hispanic Women in Texas: Effective Strategies from Research and Practice
}

\author{
Maria E. Fernandez ${ }^{\mathrm{a}}$, Lara S. Savas ${ }^{\mathrm{a}}$, Erica Lipizzi ${ }^{\mathrm{a}}$, Jennifer S. Smith ${ }^{\mathrm{b}}$, and Sally W. \\ Vernon ${ }^{a}$ \\ aSchool of Public Health, The University of Texas Health Science Center at Houston, Houston, \\ TX, USA \\ ${ }^{b}$ Gillings School of Global Public Health, University of North Carolina, Chapel Hill, NC, USA
}

\section{Abstract}

Purpose-Hispanic women in Texas have among the highest rates of cervical cancer incidence and mortality in the country. Increasing regular Papanicolaou test screening and HPV vaccination are crucial to reduce the burden of cervical cancer among Hispanics. This paper presents lessons learned from community-based cervical cancer control programs in Texas and highlights effective intervention programs, methods and strategies.

Methods-We reviewed and summarized cervical cancer control efforts targeting Hispanic women in Texas, focusing on interventions developed by researchers at the University of Texas, School of Public Health. We identified commonalities across programs, highlighted effective methods, and summarized lessons learned to help guide future intervention efforts.

Results-Community-academic partnerships were fundamental in all steps of program development and implementation. Programs reviewed addressed psychosocial, cultural, and access barriers to cervical cancer control among low-income Hispanic women. Intervention approaches included lay health worker (LHW) and navigation models and used print media, interactive tailored media, photonovellas, client reminders, one-on-one and group education sessions.

Conclusions-Small media materials combined with LHW and navigation approaches were effective in delivering Pap test screening and HPV vaccination messages and in linking women to services. Common theoretical methods included in these approaches were modeling, verbal persuasion, and facilitating access. Adaptation of programs to an urban environment revealed that intensive navigation was needed to link women with multiple access barriers to health services.

\section{(C) 2013 Elsevier Inc. All rights reserved.}

María E. Fernández, PhD, Associate Professor/Associate Director, The Center for Health Promotion and Prevention Research, The University of Texas Health Science Center at Houston, 7000 Fannin Street, Suite 2558, Houston, Texas 77030, Phone: 713-500-9626, Fax: 713-500-9750, maria.e.fernandez@uth.tmc.edu.

\section{Conflict of Interest}

Dr. Sally Vernon and Erica Lipizzi are supported by an unrestricted educational grant from GlaxoSmithKline (GSK). Dr. Jennifer Smith has received research grants, served on paid advisory boards, and/or been a paid speaker for GSK, Hologic Gen-Probe, and Merck.

Publisher's Disclaimer: This is a PDF file of an unedited manuscript that has been accepted for publication. As a service to our customers we are providing this early version of the manuscript. The manuscript will undergo copyediting, typesetting, and review of the resulting proof before it is published in its final citable form. Please note that during the production process errors may be discovered which could affect the content, and all legal disclaimers that apply to the journal pertain. 
Collectively, this review reveals 1) the importance of using a systematic approach for planning and adapting cervical cancer control programs; 2) advantages of collaborative academiccommunity partnerships to develop feasible interventions with broad reach; 3) the use of small media and LHW approaches and the need for tailored phone navigation in urban settings; and 4) coordination and technical assistance of community-based efforts as a way to maximize resources.

\section{Introduction}

Cervical cancer incidence rates are about 70\% higher among Hispanics than non-Hispanic whites in the U.S. [1] and among Hispanics residing in Texas compared to other states (incidence: 14 vs. 12/100,000 and mortality: 4 vs. 3/100,000). Papanicolaou (Pap) test screening decreases both incidence and mortality of cervical cancer [2], yet 25\% of Hispanic women are non-adherent to screening guidelines [3]. Similarly, despite the fact that the HPV vaccine protects against high-risk HPV and has been available since 2006 [4,5], only $33.4 \%$ of girls age 13-17 have completed the 3 dose vaccine [6]. Access barriers, lack of a regular health care provider, lower health literacy, low acculturation, lower SES, immigration status, lower education, cultural beliefs and structural barriers contribute to lower rates of Pap test screening and HPV vaccination among Hispanic women [7-9]. Interventions to improve utilization of recommended prevention and control of cervical cancer are needed for Hispanics to decrease cervical cancer-related health disparities $[1,10,11]$.

This paper describes our community-based cervical cancer control efforts in Texas aimed at increasing Pap test screening and HPV vaccination among Hispanic women. The intent of this paper is to describe selected effective cervical cancer control interventions conducted with Hispanics in Texas. While this paper does not represent a systematic review of the extant literature, it does identify and describe effective planning and participatory approaches and intervention methods and strategies across programs. We also discuss how the development of research and practice networks can build an infrastructure to improve cervical cancer control in Texas and the U.S.

\section{Effective Approaches to Increase Cervical Cancer Control}

\section{Recommended Intervention Approaches}

The Guide to Community Preventive Services (Community Guide) is a resource that provides recommendations about evidence-based public health interventions and policies [12] and includes recommendations for effective intervention strategies to increase cervical cancer screening [13]. Recommended client-directed approaches are: one-on-one education, use of small media (videos and printed materials such as letters, brochures, and newsletters to motivate people to be screened), and client reminders. Recommended provider-directed approaches include provider assessment and feedback [13,14]. Unfortunately, few studies have evaluated specific types of one-on-one approaches (e.g. lay health worker), or combinations of approaches (one-on-one with small media) to result in recommendations on specific strategies; likewise, there are too few studies with Hispanic women to make specific recommendations for Hispanics generally or for specific Hispanic subpopulations. 
While the Community Guide provides recommendations for increasing adolescent vaccination, it does not provide guidance for increasing HPV vaccination specifically [15]. Recommendations include 1) home visits, reducing out-of pocket costs, and vaccination through school-based programs to enhance access; 2) incentives, client reminder systems, and school immunization requirements to enhance community demand; and 3) immunization information systems, provider reminders, provider assessment and feedback, and standing orders. Additionally, the published literature show that although patient reminders may not be effective in increasing vaccine uptake [16] they can increase HPV vaccine series completion [16-18]. Further, provider-directed strategies (provider reminders, education, and feedback) were most effective for increasing HPV vaccine uptake, whereas family-directed strategies (parent reminders and education) promoted completion of all three doses [19]. Groups receiving both provider- and family-directed strategies had the highest vaccination rates [19].

\section{Developing an Infrastructure for Cervical Cancer Control in Texas}

\section{Community-Academic Partnerships}

We have formed several networks of partners to address cancer control in Texas, and more recently have developed partnerships for cervical cancer control specifically. The Cancer Prevention and Control Research Network (CPCRN), established in 2002 with funding from the Centers for Disease Control and Prevention (CDC) and the National Cancer Institute (NCI), includes 10 centers in 9 states [20]. Each center has a variety of academic, health care provider and community organization partners who work together to accelerate the use of evidence-based cancer control programs in communities [21]. In Texas, we established Latinos in a Network for Cancer Control (LINCC) as our CPCRN and developed a collaborative cancer control research and practice agenda which led to new collaborations, funding, and research to reduce cervical cancer in Texas.

The Community Networks Program Centers (CNPC) funded through NCI cooperative agreements with 25 academic sites across the U.S. [22] is focused on reducing cancerrelated disparities through community-based education, training, and research. As a joint program of the University of Texas School of Public Health (UTSPH) and MD Anderson Cancer Center (MDACC), our CNPC, Latinos Contra el Cancer, focuses on increasing cancer control in Houston, El Paso, and the Lower Rio Grande Valley of Texas. As such, we have worked with community partners to develop and implement cancer control programs in these communities. While both LINCC and the CNPC served to bring together academic and community partners to develop cancer control programs, an increased focus on cervical cancer was needed.

\section{Cervical Cancer-Free Texas Initiative}

Texas joined the Cervical Cancer-Free America coalition in April 2011 with the goal of reducing or eliminating cervical cancer in Texas by increasing regular Pap testing and HPV vaccination rates. Cervical Cancer-Free Texas (CCFTx) collaborates with existing organizations and cancer prevention and control stakeholders throughout the state and provides an infrastructure through which evidence-based cervical cancer control programs 
are identified or developed, disseminated, and sustained. It offers the unique opportunity to maximize the impact of existing efforts throughout the state by leveraging resources and building a coordinated approach to cervical cancer control. Below, we describe several efforts developed and implemented through the networks described above (CPCRN, CNPC, and CCFTx) and highlight intervention methods and delivery strategies shown to increase cervical cancer control among Hispanics in Texas.

\section{Research-tested Intervention Approaches in Hispanic Communities Increasing Cervical Cancer Screening among Hispanic Farmworkers}

Funded through a CDC collaborative agreement, Cultivando la Salud (CLS) was developed by the National Center for Farmworker Health (NCFH) in collaboration with the UTSPH Center for Health Promotion and Prevention Research (CHPPR) [23]. The CLS program sought to modify factors influencing Pap testing through a culturally competent program delivered by lay health workers (LHWs) to Hispanic women 50 and older in farmworker communities. The LHW model is based on peer health education in which community members deliver educational messages and connect women with health care resources [24$32]$ and has been effectively used to increase access to health services including Pap test screening [27,30,33-37]. The CLS program used Community Guide recommended approaches including one-on-one education and small media strategies for increasing screening [38]. We developed CLS using Intervention Mapping (IM), a systematic approach to developing theory and evidence-based health promotion programs. CLS materials included those directed at both the target community (Hispanic women living in farmworker communities), program adopters (clinic directors and outreach coordinators), and program implementers (LHWs). They included: 1) a Program Manual designed to influence adoption and implementation (e.g. instructions for starting a LHW program); 2) a Breast and Cervical Cancer Training Curriculum for clinic staff to train LHWs; 3) a Teaching Guide for LHWs to carry out educational sessions; and 4) Educational Materials (i.e., a flipchart and DVD with information and motivational messages on screening recommendations, role model stories, and provider communication.

We used a pre-post comparison group design with matched pairs of communities in two geographic regions to evaluate the program [39]. Participants were recruited by trained data collectors through door-to-door outreach, and the intervention was also delivered at participants' homes. At six-month follow-up, screening completion was higher among women in the intervention compared with control group for mammography $(40.8 \% \mathrm{v}$. $29.9 \%$ ) and Pap test (39.5\% v. 23.6\%) [39-42]. Program materials and messages also successfully changed screening knowledge, self-efficacy, perceived risk, and decisional balance [39-42]. A subsequent study demonstrated the effectiveness of the program on increasing repeat screening (56\% in the intervention condition completed screening versus $36 \%$ in the comparison condition) [43,44]. Another study that implemented the CLS program in Hays County, Texas, showed that $72 \%$ of participants completed screening, a higher rate than in the original intervention trial [45]. 


\section{AMIGAS (Ayudando a Las Mujeres con Información, Guía y Amor para su Salud)}

AMIGAS is a LHW-delivered program to increase Pap test screening among women of Mexican origin [46,47]. Like CLS, the AMIGAS program was developed using IM [23] and included both one-on-one education and small media strategies [12] but focused on younger women. Program components were: a video novella; a flip chart; games and activities that included cards to help LHWs identify women's stage of readiness to be screened; a contract sheet titled "mi promesa" (my promise); and a training manual for LHWs. The intervention was delivered one-on-one by LHWs.

AMIGAS was evaluated in a randomized controlled trial conducted in three sites: El Paso, Texas, located along the US/Mexico border; Houston, Texas, a large urban area; and Yakima Valley, Washington, a rural farming community. Participants were recruited using flyers and in-person contact in a variety of locations including beauty salons, jewelry stores, bakeries, laundromats, schools, community centers, churches, and retail stores. Women were randomized to one of four groups: video and flip chart, video alone, flip chart alone, or a group that did not receive education from a LHW. In the intent-to-treat analysis, women in all three intervention groups were more likely to be screened compared with the group not receiving LHW education: $52.3 \%, 41.3 \%, 45.5 \%, 24.8 \%$ in the video and flip chart, video only, flip chart only and control groups respectively. There was no statistically significant difference in screening among the three intervention groups. The pattern was similar for the per protocol analysis, but percentages screened were slightly higher. Likewise, the pattern was similar for the three study sites, but the difference was not statistically significant for Houston.

\section{CLS Houston}

The goal of CLS Houston was to adapt the CLS program to reach Hispanic women residing in the Greater Houston Area who were younger, more ethnically diverse, and who may experience additional barriers to screening. Using IM [23], we assessed community needs and resources, identified determinants of screening, and developed change objectives for the program. We reviewed CLS methods and strategies and made decisions about needed changes. The IM process helped identify core elements of the program to maintain as well as new elements needed to address the contextual realties of Hispanics residing in Houston. We determined that the behaviors and determinants targeted by the original CLS program were appropriate and that the majority of messages could remain the same. However, we identified important environmental influences that could hinder cervical cancer screening in Houston. For example, due primarily to safety concerns, LHWs were less willing to recruit door-to-door and deliver the intervention in participants' homes (as implemented in rural communities). Consequently, we decided to deliver the intervention in community settings through group sessions. Another important change was addition of an intensive navigation component to help participants who needed more than a referral to local services to complete screenings. Navigation included ongoing support to address complex barriers to accessing affordable screening services in Houston. LHWs delivered telephone-based support tailored to needs of participants, providing logistic assistance, reminders, or information to help connect women to screening services. Preliminary analyses indicate that the program has been effective in increasing cervical cancer screening among participants. 


\section{Collaborating with 2-1-1 to Increase Cervical Cancer Screening}

With funding from the Cancer Prevention Research Institute of Texas (CPRIT), we collaborated with Texas 2-1-1 to increase access to cancer control services for large numbers of minority individuals with low SES. The 2-1-1 Helpline is a telephone-delivered referral program to help link callers to local and affordable programs and services to meet their basic needs (e.g., housing, health, or social services). Based on a pilot study conducted in 2011, we found that the majority (70\%) of 2-1-1 callers needed at least one cancer prevention service [48]. Many are unaware of existing health services or experience financial and transportation barriers. Trained 2-1-1 Information Specialists (IS) use a cancer prevention assessment tool to identify callers in need of services (including Pap test screening and HPV vaccination), provide referrals to low-cost and local health care providers, and provide ongoing navigation support to address barriers. The phone navigator provides tailored assistance (e.g., emotional support, motivation, health information, translation support, direct connection with health service, and assistance making appointments). This new model for increasing access takes advantage of the broad reach of 2-1-1 to provide low-cost cervical cancer control services to those most in need.

\section{Research to Practice: Review of Community-based Prevention Programs to Address Cervical Cancer}

While research studies led by academic institutions in collaboration with community partners can provide evidence of effective approaches to increase cervical cancer screening, examining grassroots efforts led by community organizations can also inform our understanding of what works in particular settings.

\section{CPRIT Prevention Projects}

Over the last four years, Texas has benefited from the availability of funding from CPRIT to address cancer prevention efforts, including cervical cancer control. Since 2010, 32 programs have been funded in Texas with the goal of expanding access to and utilization of cervical cancer screening and HPV vaccination services. CPRIT priority areas include underserved geographic areas and populations disproportionately affected by cervical cancer, many targeting high-risk minority women, particularly Hispanics. Programs are based in communities throughout Texas, including rural and underserved areas along the Texas-Mexico border (see figure 1).

These programs are aimed at reducing cervical cancer disparities in Texas with a variety of evidence-based strategies to increase HPV vaccination and/or cervical cancer screening (see figure 2).

Nearly all programs use one-on-one and/or small group approaches to deliver education in clinics or the community. Bilingual LHWs are commonly used to conduct outreach and deliver education and navigation services. Many programs offer free or low-cost preventive services. When screening or HPV vaccination cannot be provided on site, referral and/or navigation is used to connect women to these services. Client reminders are delivered 
through various methods, including mail, email, text message, and telephone. Other innovative approaches used include iPad-based education and social media networks.

The CCFTx initiative aims to maximize the impact of these cervical cancer prevention projects by convening CPRIT-funded program leaders throughout the state, organizing faceto-face meetings and facilitating networking opportunities among investigators. The group discussed ways that CCFTx and CPRIT can better share information and coordinate activities across projects. We conducted assessments of CPRIT-funded projects and shared information with grantees about intervention strategies, evaluation methods, outcome measures, and barriers to achieving goals and solutions identified by investigators. In-depth interviews are being conducted to identify best practices and successful strategies to overcoming barriers. The long-term goal is to identify successful intervention strategies that can be replicated and disseminated statewide.

\section{Discussion}

This overview of cervical cancer interventions for Hispanic women in Texas highlights a number of important lessons learned to improve cervical cancer prevention and control in Texas. These include: 1) the value of using systematic planning to develop or adapt programs; 2) the advantages of using community-based participatory research (CBPR) methods and forming community-academic partnerships; 3) the use of small media and LHW approaches, and the need for tailored phone navigation in urban settings to address access barriers; and 4) coordination and technical assistance of community-based efforts as a way to maximize resources, ensure the use of evidence-based approaches, and increase understanding about what works where.

Intervention Mapping (IM) guided the development or adaptation of the interventions described here [23]. While it is difficult to claim that without this systematic planning approach we would not have been able to develop effective interventions, we can point to specific decisions that were guided by IM during the planning phases likely influenced outcomes. Such decisions included 1) whether recommended Community Guide approaches are likely to influence change given determinants of screening and vaccination identified in the needs assessment phase, 2) whether to maintain certain components of a program during an adaptation planning effort, and 3) considerations of feasibility and context, including a close examination of program adopters and implementers, what they need to do, and what methods and strategies should be included to accelerate program use and sustainability.

A central premise of IM is CBPR, including participatory planning at all stages. The development of the cancer control networks described above greatly facilitated our ability to engage community and practice partners. The community and provider participation in the programs described here occurred at each phase, collaborating with researchers from conceptualization through delivery, data collection, and interpretation of findings. The partnerships allowed us to begin these initiatives with the full support of our communitybased cancer control partners, at least partly because cervical cancer screening and HPV vaccination had previously been identified as important goals in the LINCC, CNPC, and CCFTx research and practice agendas that were developed by jointly identifying community 
needs, resources, and goals. The development of these types of partnerships is important for extending the reach of effective interventions $[49,50]$.

We provide examples (CLS Houston and the 211 collaboration) of current adaptations of evidence-based interventions, which build on lessons learned from previous studies with Hispanics in Texas. For example, the AMIGAS study showed that the use of LHWs to recruit women and deliver education door-to-door was not effective in Houston as compared to the other rural and semi-rural sites included in the study. The formative research conducted as part of the CLS Houston study also confirmed LHWs' reluctance to recruit participants door-to-door due to safety and other concerns. Additionally, the complexity of barriers to accessing care in an urban setting with perhaps more resources, but also more confusion about services offered, transportation, and eligibility for existing programs were accentuated in Houston. Therefore, both the CLS Houston adaptation and 2-1-1 intervention included more intensive navigation by phone to connect women in the community to screening services.

Much like hospital-based patient navigators, community-based navigators, or "health coaches," provide support due to barriers that uninsured, low literacy, and minority populations encounter accessing care for routine cancer screening [51]. Examples of community-based navigation activities from the programs described here include emotional support, reminders about appointments, addressing childcare barriers, and providing information regarding eligibility and location of reduced or free health services [52]. Evidence from previous work shows that programs targeting minority populations that include navigation have increased use of preventive services for colorectal cancer screening [52-56].

In the 2-1-1 program, the "coaching calls," based on motivational and problem solving (MAPS) methods, aimed at increasing motivation for screening and/or vaccination but also included intensive navigation support to facilitate utilization of cancer prevention services. Phone navigators at the 2-1-1 Helpline were trained to use the MAPS approach [57,58], complementing the intensive Alliance of Information and Referral Systems (AIRS) training previously received through the 2-1-1 Helpline information and referral training program [59]. In the Houston-adapted CLS program, community-based navigation services were also delivered by telephone to help connect participants to cancer screenings services. To facilitate navigation, LHWs relied on databases and online resources to identify clinics providing low-cost services and eligibility for subsidized rates, and used zip code information to link participants to clinic and transportation options. This computer-assisted navigation program enabled navigators to serve women throughout the Houston area. Thus, while traditionally, the primary requirement for LHWs or navigators is that they are community members, having similar traits, such as ethnicity and socioeconomic status, or sharing similar life experiences, both the 2-1-1 and LHW navigators in the Houston-based programs needed to have communication, problem solving, telephone, and computer skills. These adapted delivery methods and strategies give rise to a potentially new "job description," requiring specific skills and specialized training to support women in urban communities. 
Finally, this paper presents lessons learned from Texas cervical cancer prevention experiences, from program development to dissemination. In general, our studies support existing recommendations for the use of LHWs delivering one-on-one and small media interventions to increase screening. Guided by social cognitive theory, common theoretical methods included in these LHW-delivered approaches were modeling, verbal persuasion, and facilitation [23]. The recent opportunity for cancer prevention research provided by CPRIT has placed the Texas cervical cancer prevention community in a unique position to advance intervention and dissemination research. The development, implementation, and evaluation of cancer prevention intervention examples from the CPRIT-funded projects provide valuable insights and lessons learned regarding program adaptation for new populations (i.e., from rural to urban) and incorporation of new prevention opportunities (e.g., adding HPV vaccination to Pap screening education programs). Moreover, the importance of using a community-academic collaborative approach to identify and understand cervical cancer disparities is reaffirmed. These collaborative partnerships bolster delivery and evaluation of community-based cervical cancer intervention research projects and provide a growing network of community-academic partnerships to reach, educate, and connect the most vulnerable and medically underserved groups to cervical cancer prevention services. The development of academic-community partnerships also opened the door for rapid response to funding opportunities that represented mutually beneficial programs and outcomes, fostering trust and sustaining growth in collaborative efforts focused on cervical cancer intervention research. Ultimately, these collaborative efforts will continue to provide important insights for the cervical cancer prevention community at-large, including reaching and delivering effective interventions to vulnerable women in diverse community settings.

Findings summarized in the programs reviewed may have limited generalizability. Since the projects described were conducted with Hispanics in Texas of primarily Mexican American descent, the findings may not be applicable to Hispanics in other parts of the country or other nations of origin. Nevertheless, while some adaptation are likely needed for successful implementation of any cervical cancer control intervention, the core elements of the programs reviewed including content and delivery approaches are likely to be similarly effective among Mexican American populations in the US. Additionally, a common element across these studies is one that improves generalizability; they were all delivered in "real world" settings assessing the effectiveness of the interventions rather than the efficacy in tightly controlled conditions. The specific adaptations needed for these programs to be acceptable and effective across populations and settings and the most effective strategies for broad scale-up of such programs represent important area of new research.

\section{Reference List}

1. American Cancer Society. Cancer Facts and Figures for Hispanics/Latinos 2009-2011. American Cancer Society; 2009. [cited 2010 Feb 18]; Available from: URL: http://www.cancer.org/acs/ groups/content/@nho/documents/document/ffhispanicslatinos20092011.pdf

2. U.S. Preventive Services Task Force. Guide to clinical preventive services. 2. Baltimore, MD: Williams \& Wilkins; 1996.

3. Texas Department of State Health Services. Texas Behavioral Risk Factor Surveillance System, Center for Health Statistics, Texas Department of State Health Services. 2011 Jun 8. [cited 2013 Aug 17]; Available from: URL: http://www.dshs.state.tx.us/chs/brfss/query/brfss_form.shtm 
4. Markowitz LE, Dunne EF, Saraiya M, Lawson HW, Chesson H, Unger ER. Quadrivalent Human Papillomavirus Vaccine: Recommendations of the Advisory Committee on Immunization Practices (ACIP). MMWR Recomm Rep. 2007 Mar 23; 56(RR-2):1-24. [PubMed: 17380109]

5. Villa LL, Costa RL, Petta CA, Andrade RP, Ault KA, Giuliano AR, et al. Prophylactic quadrivalent human papillomavirus (types $6,11,16$, and 18) $\mathrm{L} 1$ virus-like particle vaccine in young women: a randomised double-blind placebo-controlled multicentre phase II efficacy trial. Lancet Oncol. 2005 May; 6(5):271-8. [PubMed: 15863374]

6. National and state vaccination coverage among adolescents aged 13-17 years - United States, 2012. MMWR Morb Mortal Wkly Rep. 2013 Aug 30; 62(34):685-93. [PubMed: 23985496]

7. Luque JS, Castaneda H, Tyson DM, Vargas N, Proctor S, Meade CD. HPV awareness among Latina immigrants and Anglo American women in the southern U.S.: cultural models of cervical cancer risk factors and beliefs. NAPA Bull. 2010 Nov 1; 34(1):84-104. [PubMed: 21116468]

8. Akers AY, Newmann SJ, Smith JS. Factors underlying disparities in cervical cancer incidence, screening, and treatment in the United States. Curr Probl Cancer. 2007 May; 31(3):157-81. [PubMed: 17543946]

9. Fernandez ME, Allen JD, Mistry R, Kahn JA. Integrating clinical, community, and policy perspectives on human papillomavirus vaccination. Annu Rev Public Health. 2010; 31:235-52. [PubMed: 20001821]

10. McDougall JA, Madeleine MM, Daling JR, Li CI. Racial and ethnic disparities in cervical cancer incidence rates in the United States, 1992-2003. Cancer Causes Control. 2007 Dec; 18(10):117586. [PubMed: 17805982]

11. Downs LS, Smith JS, Scarinci I, Flowers L, Parham G. The disparity of cervical cancer in diverse populations. Gynecol Oncol. 2008 May; 109(2 Suppl):S22-S30. [PubMed: 18482555]

12. Centers for Disease Control and Prevention. Guide to Community Preventive Services: Systematic Reviews and Evidence-Based Recommendations [home page]. 2013 Jul 1. [cited 2013 Aug 1]; Available from: URL: http://www.thecommunityguide.org/

13. Sabatino S, Lawrence B, Elder R, Mercer S, Wilson K, Devinney B, et al. Effectiveness of interventions to increase screening for breast, cervical and colorectal cancers: Nine updated systematic reviews for the Guide to Community Preventive Services. Am J Prev Med. 2012 Jul; 43(1):97-118. [PubMed: 22704754]

14. Cancer Prevention and Control. The Guide to Community Preventive Services. 2012 Mar 29. Available from: URL: http://www.thecommunityguide.org/cancer/index.html

15. Increasing appropriate vaccination. Guide to Community Preventive Services. 2013 Jul 22. Available from: URL: www.thecommunityguide.org/vaccines/index.html

16. Szilagyi PG, Albertin C, Humiston SG, Rand CM, Schaffer S, Brill H, et al. A Randomized Trial of the Effect of Centralized Reminder/Recall on Immunizations and Preventive Care Visits for Adolescents. Acad Pediatr. 2013 Jan 9.

17. Kharbanda EO, Stockwell MS, Fox HW, Andres R, Lara M, Rickert VI. Text message reminders to promote human papillomavirus vaccination. Vaccine. 2011 Mar 21; 29(14):2537-41. [PubMed: 21300094]

18. Suh CA, Saville A, Daley MF, Glazner JE, Barrow J, Stokley S, et al. Effectiveness and net cost of reminder/recall for adolescent immunizations. Pediatrics. 2012 Jun; 129(6):e1437-e1445. [PubMed: 22566415]

19. Fiks AG, Grundmeier RW, Mayne S, Song L, Feemster K, Karavite D, et al. Effectiveness of Decision Support for Families, Clinicians, or Both on HPV Vaccine Receipt. Pediatrics. 2013 May 6.

20. Cancer Prevention and Control Research Network. Cancer Prevention and Control Research Network. 2013. [cited 2103 Apr 7]; Available from: URL: http://cpcrn.org/

21. Harris JR, Brown PK, Coughlin S, Fernandez ME, Hebert JR, Kerner J, et al. The cancer prevention and control research network. Prev Chronic Dis. 2005 Jan.2(1):A21. [PubMed: 15670474]

22. National Cancer Institute. Community Networks Program (CNP) Program Information. 2009. [cited 2013 Apr 7]; Available from: URL: http://crchd.cancer.gov/cnp/program-information.html 
23. Bartholomew, LK.; Parcel, GS.; Kok, G.; Gottlieb, NH.; Fernandez, ME. Planning Health Promotion Programs: An Intervention Mapping Approach. San Francisco: Jossey-Bass; 2011.

24. Castro FG, Elder J, Coe K, Tafoya-Barraza HM, Moratto S, Campbell N, et al. Mobilizing churches for health promotion in Latino communities: Companeros en la Salud. J Natl Cancer Inst Monogr. 1995; (18):127-35. [PubMed: 8562213]

25. Rodriguez R, McFarlane J, Mahon J, Fehir J. De Madres a Madres: a community partnership to increase access to prenatal care. Bull Pan Am Health Organ. 1993; 27(4):403-8. [PubMed: 8312964]

26. May KM, Mendelson C, Ferketich S. Community empowerment in rural health care. Public Health Nurs. 1995 Feb; 12(1):25-30. [PubMed: 7899220]

27. Meister JS, Warrick LH, de Zapien JG, Wood AH. Using lay health workers: Case study of a community-based prenatal intervention. J Community Health. 1992; 17(1):37-51. [PubMed: 1564139]

28. Ramos IN, May M, Ramos KS. Environmental health training of promotoras in colonias along the Texas- Mexico border. Am J Public Health. 2001 Apr; 91(4):568-70. [PubMed: 11291367]

29. Navarro AM, Senn KL, McNicholas LJ, Kaplan RM, Roppe B, Campo MC. Por La Vida model intervention enhances use of cancer screening tests among Latinas. Am J Prev Med. 1998 Jul; 15(1):32-41. [PubMed: 9651636]

30. Alcalay R, Alvarado M, Balcazar H, Newman E, Huerta E. Salud para su Corazon: a communitybased Latino cardiovascular disease prevention and outreach model. J Community Health. 1999 Oct; 24(5):359-79. [PubMed: 10555925]

31. Lacey, Y.; Blondet, L. The Final Report of the National Community Health Advisor Study. 1998 Jun.

32. Bailey JE, Coombs DW. Effectiveness of an Indonesian model for rapid training of Guatemalan health workers in diarrhea case management. J Community Health. 1996 Aug; 21(4):269-76. [PubMed: 8842889]

33. Warrick LH, Wood AH, Meister JS, de Zapien JG. Evaluation of a peer health worker prenatal outreach and education program for Hispanic farmworker families. J Community Health. 1992 Feb; 17(1):13-26. [PubMed: 1564136]

34. Watkins EL, Harlan C, Eng E, Gansky SA, Gehan D, Larson K. Assessing the effectiveness of lay health advisors with migrant farmworkers. Fam Community Health. 1994; 16(4):72-87.

35. Woodruff SI, Talavera GA, Elder JP. Evaluation of a culturally appropriate smoking cessation intervention for Latinos. Tob Control. 2002; 4(361):367.

36. Morris DL, Felkner M, McLean CH. Pap screening in the Rio Grande Valley: A case study. Fam Community Health. 1994; 17(3):1-14.

37. Hansen LK, Feigl P, Modiano MR, Lopez JA, Escobedo SS, Moinpour CM, et al. An educational program to increase cervical and breast cancer screening in Hispanic women: a Southwest Oncology Group study. Cancer Nurs. 2005 Jan; 28(1):47-53. [PubMed: 15681982]

38. Task Force on Community Preventive Services. Guide to community preventive services: Systematic reviews and evidence based recommendations. 2008 Aug 18. [cited 2008 Sep 18]; Available from: URL: http://www.thecommunityguide.org/

39. Fernandez ME, Gonzales A, Tortolero-Luna G, Williams J, Saavedra-Embesi M, Chan W, et al. Effectiveness of Cultivando la Salud: A breast and cervical cancer screening promotion program for low-income Hispanic women. Am J Public Health. 2009 May; 99(5):936-43. [PubMed: 19299678]

40. Final Report. Buda, TX: National Center for Farmworker Health; 2003. Cultivando La Salud: Breast and Cervical Cancer Replication and Dissemination Program.

41. Fernandez ME, Gonzales A, Tortolero-Luna G, Partida S, Bartholomew LK. Using Intervention Mapping to develop a breast and cervical cancer screening program for Hispanic farmworkers: Cultivando La Salud. Health Promot Pract. 2005 Oct; 6(4):394-404. [PubMed: 16210681]

42. Fernandez, ME.; Gonzales, A.; Tortolero, G.; Partida, S.; Bartholomew, LK. Cultivando la Salud: A breast and cervical cancer screening program for Hispanic farmworker women. In:

Bartholomew, LK.; Parcel, GS.; Kok, G.; Gottlieb, NH., editors. Intervention Mapping: Designing 
Theory- and Evidence -Based Health Promotion Programs. Vol. 2. San Francisco, CA: Jossey Bass; 2006. p. 606-645.

43. Final Report. Buda, TX: National Center for Farmworker Health; 2005. Cultivando La Salud: Breast and Cervical Cancer Replication and Dissemination Program, Initial and Repeat Screening.

44. Susan, G. Komen Breast Cancer Foundation. Breast Cancer Research Final Progress Report. Buda, TX: National Center for Farmworker Health; 2005 Jul.

45. Susan, G. Komen Breast Cancer Foundation. Hays County Cultivando La Salud Program Final Report. Buda, TX: National Center for Farmworker Health; 2008 Mar.

46. Byrd TL, Wilson KM, Smith JL, Heckert A, Orians C, Vernon SW, et al. Using intervention mapping as a participatory strategy: development of a cervical cancer screening intervention for Hispanic women. Health Educ Behav. 2012 Mar 1; 39(5):603-11. [PubMed: 22388451]

47. Byrd TL, Wilson KM, Smith JL, Coronado G, Vernon SW, Fernandez-Esquer ME, et al. AMIGAS: A multi-city, multi-component cervical cancer prevention trial among Mexican American women. Cancer. 2013 Apr 1; 119(7):1365-72. [PubMed: 23280399]

48. Purnell JQ, Kreuter MW, Eddens KS, Ribisl KM, Hannon P, Williams RS, et al. Cancer control needs of 2-1-1 callers in Missouri, North Carolina, Texas, and Washington. J Health Care Poor Underserved. 2012 May; 23(2):752-67. [PubMed: 22643622]

49. Wallerstein N, Duran B. Community-based participatory research contributions to intervention research: the intersection of science and practice to improve health equity. Am J Public Health 2010 Apr 1; 100( Suppl 1):S40-S46. [PubMed: 20147663]

50. Proctor EK, Landsverk J, Aarons G, Chambers D, Glisson C, Mittman B. Implementation research in mental health services: an emerging science with conceptual, methodological, and training challenges. Adm Policy Ment Health. 2009 Jan; 36(1):24-34. [PubMed: 19104929]

51. Dohan D, Schrag D. Using navigators to improve care of underserved patients: current practices and approaches. Cancer. 2005 Aug 15; 104(4):848-55. [PubMed: 16010658]

52. Freeman HP. Patient navigation: a community centered approach to reducing cancer mortality. $\mathbf{J}$ Cancer Educ. 2006; 21(1 Suppl):S11-S14. [PubMed: 17020496]

53. Bradford JB, Coleman S, Cunningham W. HIV System Navigation: an emerging model to improve HIV care access. AIDS Patient Care STDS. 2007; 21( Suppl 1):S49-S58. [PubMed: 17563290]

54. Darnell JS. Patient navigation: a call to action. Soc Work. 2007 Jan; 52(1):81-4. [PubMed: 17388086]

55. Schwaderer KA, Itano JK. Bridging the healthcare divide with patient navigation: development of a research program to address disparities. Clin J Oncol Nurs. 2007 Oct; 11(5):633-9. [PubMed: 17962171]

56. Naylor K, Ward J, Polite BN. Interventions to improve care related to colorectal cancer among racial and ethnic minorities: a systematic review. J Gen Intern Med. 2012 Aug; 27(8):1033-46. [PubMed: 22798214]

57. Castro Y, Basen-Engquist K, Fernandez ME, Strong LL, Eakin EG, Resnicow K, et al. Design of a randomized controlled trial for multiple cancer risk behaviors among Spanish-speaking Mexicanorigin smokers. BMC Public Health. 2013; 13:237. [PubMed: 23506397]

58. Reitzel LR, Vidrine JI, Businelle MS, Kendzor DE, Costello TJ, Li Y, et al. Preventing postpartum smoking relapse among diverse low-income women: a randomized clinical trial. Nicotine Tob Res. 2010 Apr; 12(4):326-35. [PubMed: 20154055]

59. Online Training. AIRS. 2013. [cited 2013 Sep 24]; Available from: URL: http://www.airs.org/i4a/ pages/index.cfm?pageid $=3424$ 


\section{Research Highlights}

- A systematic planning approach to develop or adapt health intervention programs guides tailoring to new contextual and population realities

- Advantages of using community-based participatory research methods and forming community-academic partnerships to reach underserved minority populations is reviewed

- Review use of small media and LHW approaches to deliver phone navigation to address access barriers in urban Hispanic populations 


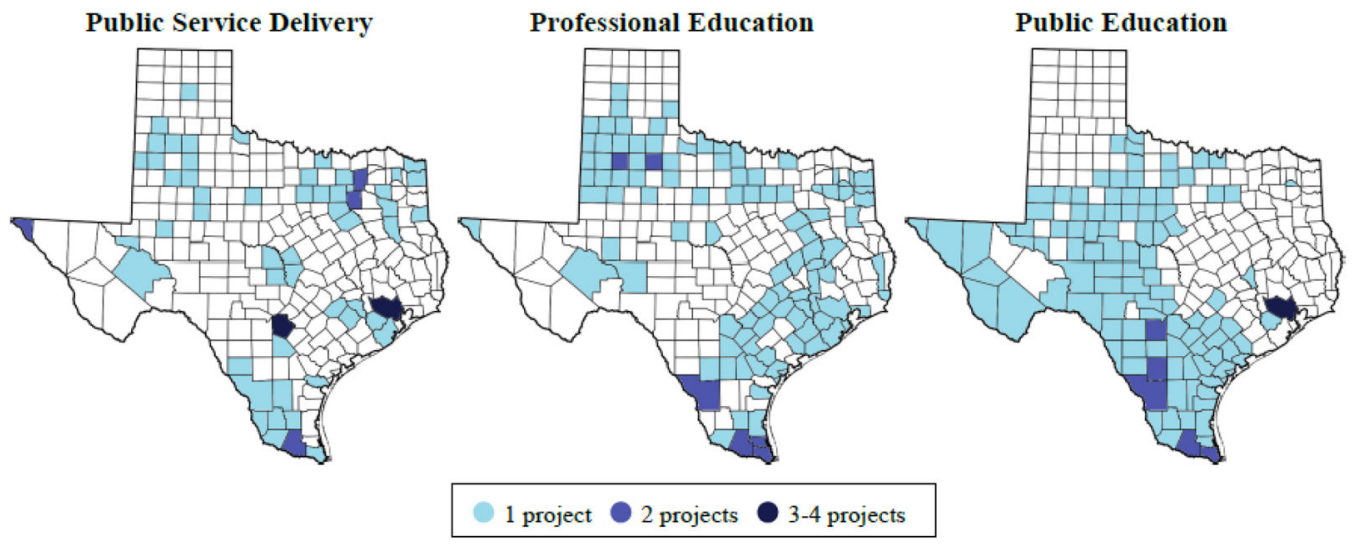

Figure 1.

Counties reached by CPRIT cervical cancer prevention projects. Data obtained from the Cancer Prevention Research Institute of Texas (CPRIT) as of January 2013. 


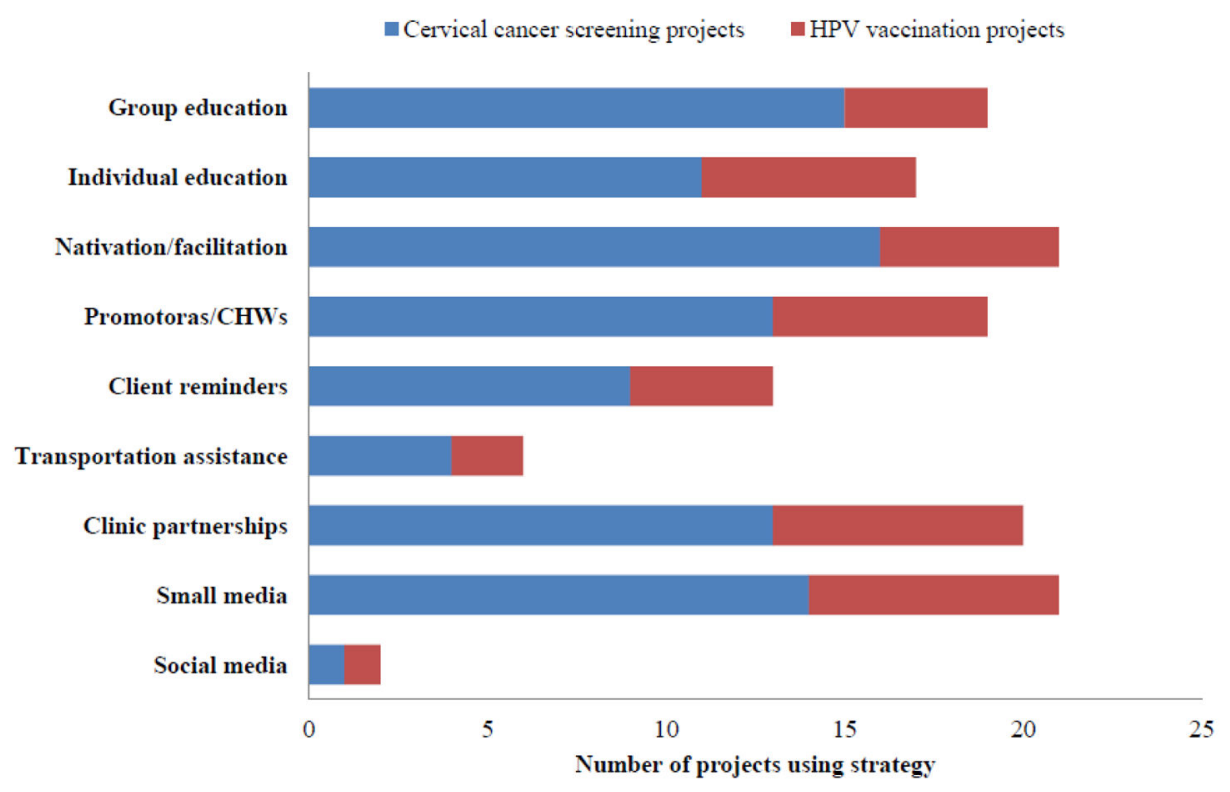

Figure 2.

Intervention strategies used by CPRIT cervical cancer prevention grantees. 